\title{
Pemilihan Model Terbaik Dalam Analisa Regresi Studi Kasus Pendugaan Bobot Hidup Sapi Persilangan Simental Dengan Sapi PO Berdasarkan Ukuran - Ukuran Tubuh.
}

\author{
Yurnalis
}

\begin{abstract}
The objective of the research was to find out the best model of regression equation in predicting body weight of F2 by using body measurement parameters of Simental and Ongole Cross cattle. Eighty two bulls kept by farmer in Padang Panjang, West Sumatra were used in this study. Each bull was measured for their body parametrs. The parameter measured included body wight $(B H)$, body length $(P B)$, thorax circle (LD), shoulder high (TP) and age in month (US). The data were than statistically analysis by regressin analysis, where the dependent variable was $B H$, while the independent were $P B, L D, T P$ and US. Criteria for choosing the best equation were $R^{2}, R^{2}$ Adjusted, Mean square Error (MSE), and Cp Mallow's. The best equation with one independence variable is $B H=6,024 L D-602,996$, the best model with two independence variable is $B H=3,991 P B+3,809 L D-775,596$, the best model with three independence variable is $B H=3,23 P B+3,508 L D+1,855 T P-852,371$ and the best model with four independence variable is $B H=3,20 P B+3,597 L D+1,836 T P-0,181$ US - 657.598. The best equation for estimation of body weight was found by using three independence variable of $B H=3,23 P B+3,508 L D+1,855 T P-852,371$.
\end{abstract}

Key words: regression equation, Simental, Onggole Cross.

\section{Pendahuluan}

Penggunaan analisa regresi
dalam peramalan bobot hidup berdasarkan ukuran-ukuran tubuh ternak sapi sudah lama dilakukan. Demikian juga telah banyak rumusrumus pendugaan bobot hidup berdasarkan ukuran-ukuran tubuh yang telah dihasilkan seperti rumus Schoorl, rumus Winter yang dilaporkan Guntoro (2002), dan rumus pendugaan bobot hidup sapi bali oleh Ida Bagus Djagra dalam Santoso (2005). Hanya saja rumusrumus tersebut berlaku untuk jenis sapi tertentu saja. Sedangkan untuk sapi sapi persilangan belum banyak penelitian yang dilakukan. Berikut akan dijelaskan strategi pemilihan model regresi terbaik dalam pendugaan bobot hidup ternak berdasarkan ukuran - ukuran tubuh.
Analisa regresi adalah suatu analisis yang memanfaatkan hubungan antara dua atau lebih peubah kuantitatif. Model regresi adalah model yang dapat digunakan untuk mengetahui hubungan antara satu peubah tidak bebas dengan satu atau lebih peubah tidak bebas. Hubungan linier antara suatu respon (peubah tidak bebas) dengan $\mathrm{k}$ peubah bebas dinyatakan sebagai berikut:

$y_{i}=\beta_{0}+\beta_{i} x_{1 i}+\beta_{2} x_{2 i}+\ldots+\beta_{k} x_{k i}+\varepsilon_{i}$ Persamaan diatas menyatakan respon $\mathrm{ke} \cdot \mathrm{i}$ dari y tergantung secara linier terhadap nilai-nilai dari $\mathrm{k}$ peubah bebas $\mathrm{x}_{1}, \mathrm{x}_{2}, \ldots, \mathrm{x}_{\mathrm{k}}$ berdasarkan hubungan linier dalam parameter $\beta_{0}$, $\beta_{1}, \ldots, \beta_{k}$. Dimana peubah peubah bebas diasumsikan diukur tanpa kesalahan, serta $\varepsilon_{i}$ yang merupakan galat diasumsikan menyebar secara 
normal dengan rata-rata nol dan ragam $\left(\sigma^{2}\right.$.) yang homogen

Permasalah yang sering dihadapi dalam pembentukan model regresi adalah pemilihan model regresi terbaik berdasarkan data yang yang digunakan. Seperti diketahui model regresi yang diperoleh merupakan pendekatan terhadap hubungan yang sesungguhnya antara respon dengan peubah peubah bebas yang umumya tidak pernah diketahui, kecuali jika semua data populasi dapat dikumpulkan. Untuk itu diperlukan kriteria statistika yang dapat digunakan untuk menentukan model regresi terbaik.

Neter et. al. mengemukan ada 4 langkah dalam pembentukan model regresi yaitu:

1. Persiapan dan pengumpulan data.

2. Pengurangan banyaknya peubah bebas.

3. Seleksi dan fiting model.

4. Validasi model.

Penelitian ini membahas pemilihan model regresi terbaik berdasarkan seleksi dan fitting model dalam pendugaan bobot hidup ternak berdasarkan ukuran - ukuran tubuh dan umur ternak.

Beberapa kriteria statistik yang dapat digunakan adalah Kuadrat tengah error (Allen, D.M. 1971), kefesien determinansi $\left(R^{2}\right)$, koefesien determinansi terkoreksi ( $\mathrm{R}^{2}$ Adjusted), dan $\mathrm{Cp}$ Mallow (Mallows, C.L. 1973). Kuadrat tengah error merupakan penduga keragaman galat (error), model yang terbaik adalah model dengan keragaman galat yang terkecil. Koefesien determinansi menunjukkan proporsi keragaman yang dapat diterangkan oleh model, sehingga makin besar koefesien determinansi makin baik modelnya. Sedangkan Cp Mallow's membantu kita menentukan berapa banyak peubah bebas yang seharusnya digunakan dalam model regresi terbaik.

\section{Materi dan Metoda Penelitian.}

Penelitian ini dilakukan di Kota Madya Padang Panjang dengan menggunakan 82 ekor sapi jantan persilangan Simental dan sapi peranakan Ongoole (PO) dari berbagai tingkat umur. Peubah yang diamati adalah bobot hidup (BH), panjang badan (PB), lingkar dada (LD), tinggi pundak (TP) dan umur sapi dalam bulan (US). Data peubah Bobot hidup sebagai respon (peubah tidak bebas) diregresikan dengan dengan peubah panjang badan, lingkar, dada, panjang badan serta umur sebagai peubah bebas.

Model regresi yang dipertimbangkan dalam menduga hubungan antara respon dengan peubah bebas adalah :

1. $y=\beta_{0}+\beta_{1}(P B)$

2. $y=\beta_{0}+\beta_{1}(L D)$

3. $y=\beta_{0}+\beta_{1}(T D)$

4. $y=\beta_{0}+\beta_{1}(U S)$

5. $y=\beta_{0}+\beta_{1}(P B)+\beta_{2}(L D)$

6. $y=\beta_{0}+\beta_{1}(P B)+\beta_{2}(T P)$

7. $y=\beta_{0}+\beta_{1}(P B)+\beta_{2}(U S)$

8. $y=\beta_{0}+\beta_{1}(L D)+\beta_{2}(T P)$

9. $y=\beta_{0}+\beta_{1}(L D)+\beta_{2}(U S)$

10. $y=\beta_{0}+\beta_{1}(T P)+\beta_{2}(U S)$

$11 y=\beta_{0}+\beta_{1}(P B)+\beta_{2}(L D)+\beta_{3}(T P)$

12. $y=\beta_{0}+\beta_{1}(P B)+\beta_{2}(L D)+\beta_{3}(U S)$

13. $y=\beta_{0}+\beta_{1}(P B)+\beta_{2}(T P)+\beta_{3}(U S)$

14. $y=\beta_{0}+\beta_{1}(L D)+\beta_{2}(T P)+\beta_{3}(U S)$ 
15. $y=\beta_{6}+\beta_{1}(P B)+\beta_{2}\left(L D+\beta_{3}(T P)+\beta_{4}(U S)\right.$

Kriteria seleksi untuk untuk memilih model regresi terbaik adalah:

1. Koefesien detreminasi, dengan rumus:

$R^{2}=1-\frac{J K E}{J K T}$

Dimana JKE adalah jumlah kuadrat error, JKT adalah jumlah kuadrat total.

2. Koefesien determinansi terkoreksi, dengan rumus:

$R_{\text {Adjusted }}^{2}=1-\frac{J K E /(n-p)}{J K T /(n-1)}$

Dimana $\mathrm{n}$ adalah banyaknya pengamatan, dan $\mathrm{p}$ banyaknya koefesien regresi.

3. Kuadrat tengah error.

$$
s^{2}=\frac{J K E}{n-p}
$$

4. C $\mathrm{C}_{\mathrm{p}}$-Mallow's.

$$
C_{p}=p+\frac{\left(s^{2}-\sigma^{2}\right)(n-p)}{\sigma^{2}}
$$

Dimana $\mathrm{s}^{2}$ adalah KTE dari model yang digunakan, sedangkan $\sigma^{2}$ adalah KTE dari model penuh (menggunakan semua peubah bebas).

\section{Hasil dan Pembahasan}

Dari hasil pengolahan data pada tabel 1 berikut ditampilkan rata - rata, standar deviasi serta maksimum dan minimum dari bobot hidup (BH), lingkar dada (LD), tinggi pundak (TP) serta umur sapi (US) dalam bulan dan pada tabel 2 ditampilkan koefisien antara berat hidup dengan ukuran - ukuran tubuh. Dalam analisis ini digunakan 4 peubah bebas sehingga ada $2^{4}-1=$ 15 kemungkinan model yang diperoleh. Hasil analisis dengan menggunakan SAS for windows release 9 ditampilkan pada Table 3 .

Tabel 1. Rata - rata, Standar Deviasi, Maksimum dan Minimum dari Berat Hidup dan Ukuran - ukuran Tubuh

\begin{tabular}{cccrrr}
\hline Variabel & N & Rata - rata & Std Dev & Minimum & Maksimum \\
\hline BH & 82 & 471.927 & 191.300 & 174.00 & 864.00 \\
PB & 82 & 142.366 & 19.343 & 88.00 & 181.00 \\
LD & 82 & 178.372 & 26.674 & 120.00 & 231.00 \\
TP & 82 & 128.638 & 14.252 & 98.00 & 176.00 \\
US & 82 & 21.232 & 13.429 & 4.00 & 48.00 \\
\hline
\end{tabular}

Tabel 2. Koefisien Korelasi antar Ukuran Tubuh dengan Bobot Hidup

\begin{tabular}{cccccc}
\hline & BH & PB & LD & TP & US \\
\hline BH & 1.00000 & 0.90652 & 0.93434 & 0.85525 & 0.68505 \\
PB & 0.90652 & 1.00000 & 0.85142 & 0.84391 & 0.58837 \\
LD & 0.93434 & 0.85142 & 1.00000 & 0.81122 & 0.78891 \\
TP & 0.85525 & 0.84391 & 0.81122 & 1.66666 & 0.56458 \\
US & 0.69505 & 0.58837 & 0.78891 & 0.56458 & 1.00000 \\
\hline
\end{tabular}


Tabel 3. Hasil Analisis Regresi Data Bobot Hidup dengan Ukuran Tubuh

\begin{tabular}{|c|c|c|c|c|c|c|c|c|c|c|}
\hline No & $\begin{array}{c}\text { Peubah Yang } \\
\text { digunakan }\end{array}$ & $\mathbf{B}_{0}$ & $\mathbf{B}_{0}$ & $b_{0}$ & $b_{0}$ & $b_{0}$ & $\mathrm{~s}^{2}$ & $\mathrm{R}^{2}$ & $\mathrm{R}^{2}$ Adj & $C p$ \\
\hline 1 & 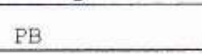 & $-804,457$ & 8,966 & & & & 6603,456 & 0,822 & 0,820 & 99,634 \\
\hline 2 & LD & $-602,996$ & & 6,024 & & & 4705,950 & 0,873 & 0,871 & 48,591 \\
\hline 3 & TF & $-1005,36$ & & & 11,480 & & 9950,556 & 0,732 & 0,728 & 189,672 \\
\hline 4 & us & 261,701 & & & & 9,902 & 19153,000 & 0,483 & 0,477 & 437,219 \\
\hline 5 & PB LD & $-775,596$ & 3,991 & 3,809 & & & 3084,681 & 0,918 & 0,916 & 5,941 \\
\hline 6 & $\mathrm{~PB} T \mathrm{TP}$ & $-973,456$ & 6,349 & & 4,208 & & 5625,721 & 0,850 & 0,846 & 73,441 \\
\hline 7 & PB US & $-674,391$ & 7,527 & & & 3,523 & 5186,837 & 0,862 & 0,858 & 61,783 \\
\hline 8 & LD TP & $-828,559$ & & 4,535 & 3,819 & & 3726,763 & 0,901 & 0,898 & 22,997 \\
\hline 9 & LD US & $-669,849$ & & 6,590 & & $-1,587$ & 4589,754 & 0,878 & 0,875 & 45,922 \\
\hline 10 & TP US & $-795,811$ & & & 9,120 & 4,437 & 7596,504 & 0,798 & 0,792 & 125,793 \\
\hline 11 & PB LD TP & $-852,371$ & 3,230 & 3,508 & 1,855 & & 2937,968 & 0,923 & 0,920 & 3,056 \\
\hline 12 & PB LD US & $-786,952$ & 3,919 & 3,97 & & $-0,341$ & 3116,555 & 0,918 & 0,915 & 7,740 \\
\hline 13 & PB TP US & $-829,653$ & 5,503 & & 3,509 & 3,135 & 4524,035 & 0,881 & 0,876 & 44,655 \\
\hline 14 & LD TP US & $-853,075$ & & 4,892 & 3,651 & $-0,813$ & 3729,851 & 0,902 & 0,898 & 23,825 \\
\hline 15 & PB LD TP US & $-657,598$ & 3,200 & 3,597 & 1,836 & $-0,181$ & 2973,960 & 0,923 & 0,919 & 5,000 \\
\hline
\end{tabular}

Dari Tabel diatas terlihat nilainilai $\mathrm{R}^{2}, \mathrm{R}^{2}$ Adjusted terbesar untuk tiap himpunan yang memuat satu, dua, tiga, dan empat peubah bebas adalah sebagai berikut:

1. Untuk himpunan dengan satu peubah bebas $\mathrm{LD}$ dengan $\mathrm{R}^{2}=$ 0,873 dan $\mathrm{R}^{2}$ Adjusted $=0,871$ (model 2)

2. Untuk himpunan dengan dua peubah bebas $\mathrm{PB}, \mathrm{LD}$ dengan $\mathrm{R}^{2}$ $=0,918$ dan $R^{2}$ Adjusted $=0,916$ (model 5)

3. Untuk himpunan dengan tiga peubah bebas PB, LD, TP dengan $\mathrm{R}^{2}=0,923$ dan $\mathrm{R}^{2}$ Adjusted $=0,920($ model 11$)$

4. Untuk himpunan dengan empat peubah bebas $\mathrm{PB}, \mathrm{LD}, \mathrm{TP}$, US dengan $\mathrm{R}^{2}=0,923$ dan $\mathrm{R}^{2}$ Adjusted $=0,919($ model 15$)$

Dari ke empat model di atas terlihat model 5, 11 dan 15 layak kita pilih sebagai secara statistika, karena mempunyai $\mathrm{R}^{2}$ dan $\mathrm{R}^{2}$ Adjusted yang hampir sama besar, dengan persamaan regresi terbaik berdasarkan
$\mathrm{R}^{2}$ dan $\mathrm{R}^{2}$ Adjusted adalah $\mathrm{BH}=3,230$ $\mathrm{PB}+3,508 \mathrm{LD}+1,855 \mathrm{TP}-$ 852,371

Dari tabel di atas model dengan $\mathrm{s}^{2}$ yang terkecil untuk himpunan yang memuat satu, dua , tiga , dan empat peubah bertutur-turut adalah model 2, model 5, model 11, dan model 15. Dari ke empat model ini yang terkecil $\mathrm{s}^{2}$ adalah model 11 . Model terbaik ini juga merupakan model terbaik berdasar kriteria $\mathrm{R}^{2}$ dan $\mathrm{R}^{2}$ Adjusted. Jadi model terbaik berdasarkan $\mathrm{R}^{2}$ dan $\mathrm{R}^{2}$ Adjusted dan $\mathrm{s}^{2}$ adalah $\mathrm{BH}=3,230 \mathrm{~PB}+3,508 \mathrm{LD}+$ $1,855 \mathrm{TP}-852,371$

Tabel di atas juga menampilkan nilai $\mathrm{Cp}$ untuk masing-masing model. Nilai $\mathrm{Cp}$ ini membantu kita untuk memutuskan berapa banyak peubah bebas yang seharusnya digunakan dalam regresi terbaik. Calon regresi terbaik adalah model yang nilai $\mathrm{Cp}$ terkecil yang hampir sama nilainya dengan $\mathrm{p}$ (banyaknya koefesien regresi dalam model). Untuk model dengan satu peubah nilai $\mathrm{Cp}$ nya dibandingkan dengan 2 , 
untuk model dengan dua peubah nilai $\mathrm{Cp}$ nya dibandingkan dengan 3 demikian seterusnya.

Nilai $\mathrm{Cp}$ terkecil untuk tiap himpunan yang memuat satu, dua, tiga, dan empat peubah bebas kembali adalah model 2, model 5 , model 11, dan model 15. Dengan model terbaik kembali model 11 sama seperti sebelumnya.:

Jika diperhatikan dari setiap model terbaik selalu tercakup didalamnya peubah bebas lingkar dada (LD). Hal sesuai dengan pendapat yang dikemukana oleh Cook et al (1961) bahwa ukuran lingkar dada dan lingkar perut mempunyai korelasi yang tinggi dengan bobot hidup dibanding dengan ukuran-ukuran lainnya dan Kidwel (1965) yang mengatakan penafsiran yang paling tepat dalam pendugaan bobot badan ternak sapi adalah melalui ukuran lingkar dada.

\section{Kesimpulan}

Dari hasil analisis dia ats dapat ditarik kesimpulan model regresi terbaik untuk setiap himpunan dengan peubah satu, dua, tiga, dan empat selalu memuat peubah bebas lingkar dada (LD), dan model regresi terbaik dari semua model adalah model dengan tiga peubah yaitu $\mathrm{BH}$ $=3,230 \mathrm{~PB}+3,508 \mathrm{LD}+1,855 \mathrm{TP}-$ 852,371 dengan kata lain makin tinggi panjang bada, lingkar dada dan tinggi pundak maka bobot hidup ternak juga akan meningkat.

\section{Saran}

Perlu dilakukan penelitian lanjutan untuk mencari rumus sederhana dan pembuatan pita ukur pendugaan bobot hidup berdasarkan ukuran-ukuran tubuh sapi sapi local dan sapi-sapi persilangan yang ada di Sumatera Barat.

\section{Daftar Pustaka}

Allen, D.M. (1971), "Mean Square Error of Prediction as a Criterion for Selecting Peubahs," Technometrics, 13, 469 -475.

Cook, A.C., M.K. Kohli and W.M. Dawson 1961. Relationship od Dessing Procentage in Milking Shorthorn Steer. Journal Animal Science, 10 p: 386.

Draper, N. and Smith, H. (1981), Applied Regression Analysis, Second Edition, New York: John Wiley \& Sons, Inc.

Freund, Rudolf J. and Littell, Ramon C. (1991), SAS System for Regression, Second Edition, Cary, NC: SAS Institute Inc.

Guntoro, S. 2002. Membudidayakan Sapi Bali. Kanisius, Yokyakarta.

Hocking, R.R. (1976), "The Analysis and Selection of Variable in Linear Regression," Biometrics, 32, $1-50$.
Mallows, C.L. (1973), "Some Comments on $C_{p}$," Technometrics, 15, 661 -675.

Neter, J., Wasserman, W., and Kutner, M. H. (1990), Applied Linear Statistical Models, Third Edition, Homewood, IL: Irwin.

Rawlings, J.O. (1988), Applied Regression Analysis: A Research Tool, Belmont, California: Wadsworth, Inc.

Sall, J.P. (1981), SAS Regression Applications, Revised Edition, SAS Technical Report A-102, Cary, NC: SAS Institute Inc. 
Santosa, U 2005. Tata Laksana

Pemeliharaan Ternak sapi.

Penebar swadaya, Jakarta.
Weisberg, S. (1980), Applied Linear Regression, New York: John Wiley \& Sons, Inc.

SAS Institute Inc. (1999), SAS/STAT

User's Guide, Version 7-1, Cary,

NC: SAS Institute Inc.

Alamat korespondensi: Ir. Yurnalis, M.Sc.

Jurusan Produksi Ternak, Fakultas Peternakan

Universitas Andalas, Kampus Limau Manis, Padang

Telp. 0751-74208 Fax: 0751-71464, HP: 08126628212

Diterima: 8 Mei 2007,Disetujui: 24 Mei 2007 